\title{
Influence of age, sex and season on morbidity and mortality pattern in goats under village conditions of Madhya Pradesh
}

\author{
Amit Kumar Dohare, B. Singh, Yogesh Bangar, Shiv Prasad, Dinesh Kumar and Girraj Shakya \\ Indian Veterinary Research Institute, \\ Izatnagar - 243122, Dist. Bareilly (UP), India \\ Corresponding author: Amit Kumar Dohare, email:dr.doharevet@gmail.com \\ Received: 26-10-2012, Accepted: 09-11-2012, Published online: 13-03-2013
}

\begin{abstract}
How to cite this article: Dohare AK, Singh B, Bangar Y, Prasad S, Kumar D and G Shakya (2013) Influence of age, sex and season on morbidity and mortality pattern in goats under village conditions of Madhya Pradesh, Vet. World 6(6):329-331, doi: 10.5455/vetworld.2013.329-331
\end{abstract}

\begin{abstract}
Aim: To study factors affecting morbidity and mortality pattern in goats in Chambal division of Madhya Pradesh under village conditions.

Materials and Methods: The sampling scheme adopted during study was stratified three stage random sampling and data on 549 goats were recorded.

Results: The overall morbidity and mortality rate was $20.58 \%$ and $10.20 \%$ respectively. Proportional mortality due to diarrhoea was highest (35.71\%) followed by pneumonia (28.57\%) and miscellaneous causes (12.5\%). Pattern of morbidity in male and female was almost similar. Age of goats was the most important factor and accounted for 39.29\%, 28.57\% and $32.14 \%$ mortality in 0-3 month, 6-9 month and above 9 months, respectively. The effect of season on goat mortality was significant $(p<0.05)$. The incidence of mortality were $41.07 \%, 37.5 \%$ and $21.43 \%$ in winter, rainy and summer season respectively.

Conclusion: In goats mortality was significantly influenced by age groups and suggesting that more care and attention need to be paid in kids 0-3 months age irrespective of season. Mortality due to various diseases in kids and adults could be minimized by identifying the cause and giving proper treatment.
\end{abstract}

Key words: goat, morbidity, mortality, village conditions

\section{Introduction}

Goat is one of the most important livestock species in India, which provide food and nutritional security to millions of marginal and small farmers and agricultural labourers [1]. India has 140.54 million goats which provide 4.59 million tonnes milk and 0.85 million tonnes meat [2]. Goats have short generation interval, high prolificacy, capacity to survive on sparse vegetation and easy adaptation to a wide range of climatic conditions [3].

The effect of diseases on livestock productivity includes; reduced feed intake, change in digestion and metabolism, increased morbidity and mortality, decreased rates of reproduction, weight gain and milk production. Morbidity and mortality greatly affects the economic returns from goat husbandry. Knowledge of disease pattern in different age groups and seasons will be of immense help in health management to reduce mortality. Keeping these aspects in view, the present study was undertaken to ascertain factors affecting morbidity and mortality pattern in goats under village conditions in Chambal division of Madhya Pradesh, India.

This article is an open access article licensed under the terms of the Creative Commons Attribution License (http://creativecommons. org/licenses/by/2.0) which permits unrestricted use, distribution and reproduction in any medium, provided the work is properly cited.

\section{Materials and Methods}

The Chambal division was selected for study, it consists of three districts Morena, Bhind and Sheopur. This division was divided into three strata taking each district as stratum and two blocks from each district was selected. From each block three villages were selected and ten goat owners were selected randomly from each village during period of one year (January 2010 to December 2010). Hence ultimate sample comprises 180 livestock owners. The stratified three stage random sampling was adopted for the selection of respondents. The calendar year was divided into 3 seasons: March-June (summer), July-October (Rainy) and November-February (winter). The time period from birth to death was divided into three age groups kids (0-3 months), Youngstocks (3-6 months) and adults (> 6 months).

Statistical analysis: The data were analyzed by applying Chi-square test using SPSS 11.0 software.

\section{Result and Discussion}

Factors affecting morbidity pattern: The overall morbidity rate was $20.58 \%$. As presented in table 1 , the overall incidence of diarrhoea was $32.74 \%$ followed by pneumonia (25.60\%), ectoparasites (12.39\%), goat pox $(11.50 \%)$ and anorexia $(9.73 \%)$. The miscellaneous group accounted for $7.96 \%$ morbidity and 
Table-1. Morbidity pattern (\%) in goats

\begin{tabular}{|c|c|c|c|c|c|c|c|c|c|}
\hline \multirow[t]{2}{*}{ Cause } & \multicolumn{3}{|c|}{ Age (months) } & \multicolumn{2}{|c|}{ Sex } & \multicolumn{3}{|c|}{ Season } & \multirow[t]{2}{*}{ Total } \\
\hline & $0-3$ & $3-6$ & $>6$ & Male & Female & Winter & Summer & Rainy & \\
\hline Diarrhoea & $39.47(15)$ & $33.33(11)$ & $26.19(11)$ & 35.09 (20) & $30.36(17)$ & $12.20(5)$ & $50.00(14)$ & $40.91(18)$ & $32.74(37)$ \\
\hline Pneumonia & 31.58 (12) & $27.27(9)$ & $19.05(8)$ & 28.07 (16) & $23.21(13)$ & $46.34(19)$ & 7.14 (2) & $18.18(8)$ & 25.66 (29) \\
\hline Ectoparasite & $10.53(4)$ & 9.09 (3) & $16.67(7)$ & $10.53(6)$ & $14.29(8)$ & $9.76(4)$ & $3.57 \quad(1)$ & $20.45(9)$ & $12.39(14)$ \\
\hline Goat pox & $2.63(1)$ & 9.09 (3) & $21.43(9)$ & $12.28(7)$ & $10.71(6)$ & $19.51(8)$ & 3.57 (1) & $9.09(4)$ & $11.50(13)$ \\
\hline Anorexia & $10.53(4)$ & $12.12(4)$ & 7.14 (3) & $5.26(3)$ & $14.29(8)$ & 7.32 (3) & $21.43(6)$ & $4.55(2)$ & $9.73(11)$ \\
\hline Miscellaneous & $5.26(2)$ & 9.09 (3) & $9.52(4)$ & 8.77 (5) & 7.14 (4) & $4.88(2)$ & $14.29(4)$ & $6.82(3)$ & $7.96(9)$ \\
\hline Total cases & 38 & 33 & 42 & 57 & 56 & 41 & 28 & 44 & 113 \\
\hline$\chi^{2}$ value & & $20.76^{*}$ & & 3.2 & & & $35.96^{\star \star}$ & & \\
\hline
\end{tabular}

Figure in parentheses are number of observations, NS= Non-significant, * Significant at $5 \%$ level of significance, $* *$ Significant at $1 \%$ level of significance

Table-2. Mortaliity pattern (\%) in goats

\begin{tabular}{|c|c|c|c|c|c|c|c|c|c|}
\hline \multirow[t]{2}{*}{ Cause } & \multicolumn{3}{|c|}{ Age (months) } & \multicolumn{2}{|c|}{ Sex } & \multicolumn{3}{|c|}{ Season } & \multirow[t]{2}{*}{ Total } \\
\hline & $0-3$ & $3-6$ & $>6$ & Male & Female & Winter & Summer & Rainy & \\
\hline Diarrhoea & $40.91(9)$ & $37.50(6)$ & $27.78(5)$ & $34.62(9)$ & $36.67(11)$ & $13.04(3)$ & $66.67(8)$ & $42.86(9)$ & $35.71(20)$ \\
\hline Pneumonia & $31.82(7)$ & $31.25(5)$ & $22.22(4)$ & $26.92(7)$ & $30.00(9)$ & $52.17(12)$ & 8.33 (1) & $14.29(3)$ & 28.57 (16) \\
\hline Ectoparasite & $9.09(2)$ & $12.50(2)$ & $16.67(3)$ & $15.38(4)$ & $10.00(3)$ & $8.70(2)$ & - & $23.81(5)$ & $12.50(7)$ \\
\hline Goat pox & $4.55(1)$ & $12.50(2)$ & $11.11(2)$ & $11.54(3)$ & $6.67(2)$ & $13.04(3)$ & - & $9.52(2)$ & $8.93(5)$ \\
\hline Anorexia & $9.09(2)$ & $6.25(1)$ & $5.56(1)$ & $3.85(1)$ & $10.00(3)$ & $8.70(2)$ & $8.33 \quad(1)$ & $4.76(1)$ & $7.14(4)$ \\
\hline Miscellaneous & $4.55(1)$ & - & $16.67(3)$ & $7.69(2)$ & $6.67(2)$ & $4.35(1)$ & $16.67(2)$ & $4.76(1)$ & $7.14(4)$ \\
\hline Total died & 22 & 16 & 18 & 26 & 30 & 23 & & 21 & 56 \\
\hline$\chi^{2}$ value & & $18.84^{*}$ & & & & & $22.18^{*}$ & & \\
\hline
\end{tabular}

Figure in parentheses are number of observations, NS = Non-significant, * Significant at $5 \%$ level of significance

comprising of retention of urine, tympany, pyometra and dog bite.

The interaction between age and cause exhibited that incidence of diarrhoea and pneumonia was highest in 0-3 month and lowest in above 6 months age. The incidence of goat pox was highest $(21.43 \%)$ in above 6 months age and lowest (2.63\%) in 0-3 month age similar findings were reported by Nandi et al. [4]. The difference in morbidity in different age groups were found significant $(\mathrm{p}<0.05)$. Pattern of morbidity was higher in above 6 months age (37.17\%) than 0-3 months $(33.63 \%)$ followed by 3-6 months age group (29.20\%).

The chi-square analysis showed that there was no significant difference $(p>0.05)$ between sex groups on morbidity pattern. However, male showed higher morbidity due to diarrhoea (35.09\%) and pneumonia $(28.07 \%)$. Whereas, female showed higher morbidity due to anorexia and ectoparasites (14.29\%) each as compared to their counterpart.

The analysis of morbidity pattern revealed that season had significant effect $(p<0.01)$ and it was found that incidence of pneumonia was higher in rainy $(38.94 \%)$ than winter $(36.28 \%)$ followed by summer season $(24.78 \%)$. The incidence of diarrhoea was more in summer $(50 \%)$ and rainy $(40 \%)$ as compared to winter $(12.2 \%)$. Morbidity due to pneumonia was higher in winter $(46.34 \%)$ than rainy $(18.18 \%)$ followed summer season $(7.14 \%)$.

Factors affecting mortality pattern: The overall mortality rate was $10.20 \%$. Sabapara and Deshpande [5] also recorded that overall mortality was $8.42 \%$ in goats under field conditions. As presented in Table-2, mortality due to diarrhoea $(35.71 \%)$ was more prominent followed by pneumonia $(28.57 \%)$ and miscellaneous causes $(12.5 \%)$. Similar observations were reported by Poonia and Malik [6].

The chi-square analysis showed that there was significant difference $(p<0.05)$ among different age groups on mortality pattern. Mortality was highest (39.29\%) in 0-3 months of age, then after decline in mortality was observed. This might be due to less immunity in kids, which leads to disease and ultimately mortality. This finding was in agreement with Singh et al. [7]. Mortality in 0-3 months age group was mainly due to diarrhoea $(40.91 \%)$ followed by pneumonia $(31.82 \%)$. Bobde and Barbind [8] and Soundarjan et al. [9] have reported high mortality in kids due to enteritis followed by pneumonia. Similar results were observed by Chowdhary et al. [10], where they found that $42.39 \%$ of kids died due to pneumonia followed by diarrhoea (32.61\%).

Female showed more mortality due to diseases than male, which is $53.57 \%$ and $46.43 \%$ respectively. Male kids had better rate of survival than females. Similar findings were observed by Debele et al. [11]. Results indicate that the sex groups had no significant effect $(p>0.05)$ on mortality pattern. Mortality due to pneumonia was higher in female $(30 \%)$ than male (26.92\%), whereas male showed higher mortality due to miscellaneous causes.

The death of goats was highest (41.07\%) in winter and lowest $(21.43 \%)$ in summer season. Mortality due to pneumonia was higher in winter $(52.17 \%)$ than rainy $(14.29 \%)$ followed by summer season $(8.33 \%)$. The effect of season on goat mortality was significant $(p<0.05)$. These results were closely in agreement with the findings of Mittal [12], Mazumdar et al. [13] and Lodh et al. [14] whereas, Kasem et al. [15] found 
higher mortality in rainy season. Maximum mortality in winter might be due to cold stress.

\section{Conclusion}

On the basis of results of current study, it was revealed that diarrhoea and pneumonia are major causes of morbidity, so improved hygiene and good managemental practices should be taken to reduce the occurrence of diseases. Morbidity and mortality was significantly associated with age groups, suggesting that more care and attention need to be paid in kids of 0 3 months age irrespective of season. Mortality due to various diseases in kids and adults could be minimized by identifying the cause and giving proper treatment.

\section{Authors' contribution}

$\mathrm{AD}$ and $\mathrm{BS}$ designed the study. AD conducted study and analyzed the data. SP and DK contributed in study, drafted and revised the manuscript. YB and GS compiled and analysed the data. All authors read and approved the final manuscript.

\section{Acknowledgements}

Authors are thankful to Dr. Roshan Lal Bairwa and Dr. Mahendra Semil, Veterinary Officer for providing necessary support during data collection and also thankful to farmers for providing information to conduct research.

\section{Competing interests}

Authors declare that they have no competing interest.

\section{References}

1. Kumar S., (2007) Commercialization of goat farming and marketing of goats in India. Final Report of ICAR Ad-hoc Research scheme, 2004-07, Central Institute for Research on Goats, Makhdoom, Mathura.
2. Basic Animal Husbandry Statistics (2012) Government of India, Ministry of agriculture, Department of Animal Husbandry Dairying \& Fisheries, New Delhi.

3. Sakthivel K.M., Narmatha N., Akila, N. and Uma V. (2012) Management practices followed by goat farmers in Namakkal districts of Tamil Nadu, Indian J. Small Ruminants, 18(1): 125-128.

4. Nandi D., Roy S., Bera S., Kesh S.S. and Samanta A.K. (2011) The rearing system of Black Bengal Goat and their farmers in West Bengal, India, Vet. World, 4(6): 254-257.

5. Sabapara G. P. and Deshpande S. B. (2010) Mortality Pattern in Surti goats under field condition, Vet. World. 3(4): 165166.

6. Poonia J.S. and Malik B.S. (2012) Disease pattern in mortality of Beetel goats, Indian J. Small Ruminants, 18(1): 152-153.

7. Singh M.K., Tiwari H.A., Rai B., Kumar A. and (2009) Age specific causes of kids' mortality in Jamunapari goats, Indian J. Anim. Prod. Mgmt. 24 (3-4): 46-49.

8. Bobde, S.D. and Barbind, R.P. (2002) Causes of mortality in Beetel x Osmani kids, Indian J.Small Ruminants, 8: 60-62.

9. Soundarjan C., Sivkumar, T. and Palanidorai, R. (2004) Mortality patten in Tellichery goats under intensive system, Indian J.Small Ruminant, 10: 77-79.

10. Chowdhary S.A., Bhuiyan M.S. and Faruk. A. S. (2002) Rearing Black Bengal goat under semi-intensive management 1. Physiological and Reproductive Performances. Asian-Australasian J. Anim. Sci. 15(4): 477-484.

11. Debele G., Duguma M. and Hundessa F. (2011) Effect of different factors on mortality rate of Arsi- Bale kids in Mid Rift Valley of Ethiopia. Global Veterinaria 6(1): 56-60.

12. Mittal, J.P. (1976) A study on mortality of kids, Indian. Vet. J., 53: 681-684.

13. Mazumdar N.K., Mazumdar A. and Goswami K.K. (1980) Studies on some factors affecting mortality and survival rates in Pashmina kids. Indian J. Anim. Sci. 50(3): 251-255.

14. Lodh, C., Chakrabarti, A. and Mukhopadhayay, S. (1993) Factors affecting kid mortality in West Bengal, Indian Vet. J., 70: 48-50.

15. Kashem M.A., Hossain M.A., Ahmed S.S.U. and Halim M.A. (2011) Prevalence of diseases, morbidity and mortality of Black Bengal Goats under different management systems in Bangladesh. Univ. J. Zool. Rajshahi Univ. 30: 01-04. 